\title{
Multi-sensor study of precipitable water vapor and atmospheric profiling from microwave radiometer, GNSS/MET, radiosonde, and ECMWF reanalysis in Beijing
}

\author{
Heng Hu $\odot,{ }^{\text {a, } *}$ Rongkang Yang, ${ }^{\text {a,* }}$ Wen-Chau Lee, ${ }^{\mathrm{b}}$ Yunchang Cao, ${ }^{\mathrm{a}}$ \\ Jiajia Mao, ${ }^{a}$ and Lina Gao $\odot^{a}$ \\ ${ }^{a}$ China Meteorological Administration, Meteorological Observation Center, Beijing, China \\ ${ }^{b}$ National Center for Atmospheric Research, Boulder, Colorado, United States
}

\begin{abstract}
We compare the precipitable water vapor (PWV) determined using a domestic ground-based microwave radiometer (MWR PWV) with PWV measurements from radiosondes (RS PWV), the Global Navigation Satellite System (GNSS PWV), and reanalysis from the European Centre for Medium-Range Weather Forecasts (ECMWF) (EC PWV). The MWR PWV is affected by precipitation, and thus it differs greatly from the other three observations. The correlation coefficient between the MWR PWV and RS PWV (EC PWV) is 0.934 (0.933), and the root mean square error (RMSE) is $17.19 \mathrm{~mm}(16.05 \mathrm{~mm})$, whereas the correlation coefficient between the GNSS PWV and RS PWV (EC PWV) is 0.989 (0.986), and the RMSE is $17.04 \mathrm{~mm}(15.83 \mathrm{~mm})$. The scatter distributions of the MWR PWV and the other observations show a systematic deviation that is negatively correlated with the surface air temperature. After polynomial fitting and corrections are applied, the correlation coefficients between the MWR PWV and the RS PWV and EC PWV increase to 0.993 and 0.99, and the RMSEs decrease to 14.13 and $15.86 \mathrm{~mm}$, respectively. The temperature and water vapor density profiles are retrieved from the bright temperature and can reflect the quality of the bright temperature. Because the PWV retrieved from the ground-based MWR has a linear relationship with the brightness temperature, the accuracy of the PWV can be analyzed in terms of the quality of the brightness temperature. We found that the differences in the temperature profile below $2000 \mathrm{~m}$ are smaller, whereas those in the water vapor density profile below $2000 \mathrm{~m}$ show the largest difference. This finding reflects the differences in the brightness temperature, which may be the cause of the inaccurate PWV observations. (C) The Authors. Published by SPIE under a Creative Commons Attribution 4.0 Unported License. Distribution or reproduction of this work in whole or in part requires full attribution of the original publication, including its DOI. [DOI: 10.1117/1.JRS.14.044514]
\end{abstract}

Keywords: ground-based microwave radiometer; Global Navigation Satellite System Meteorology; European Centre for Medium-Range Weather Forecasts reanalysis; radiosonde.

Paper 200357 received May 8, 2020; accepted for publication Nov. 9, 2020; published online Dec. 1, 2020.

\section{Introduction}

Water vapor is one of the main factors affecting the atmospheric greenhouse effect. ${ }^{1-3}$ Changes in water vapor strongly affect the water cycle, aerosol composition, and cloud formation. ${ }^{4}$ Water vapor is also the main driving force of weather and climate change ${ }^{5,6}$ and plays a significant role in the formation and evolution of strong, local convective weather systems. ${ }^{7}$ In addition, through the absorption and release of latent heat, the water cycle contributes to energy redistribution on Earth and affects the general and local circulation ${ }^{1,8,9}$ The accurate measurement of water vapor to better understand the water cycle has been challenging.

Although the temperature and dew point measured by radiosonde (RS) are the standard sources of data for deriving water vapor values, the global RS network is sparse, unevenly distributed, ${ }^{10}$ and expensive to operate; thus, its contribution to numerical model analysis and

*Address all correspondence to Heng Hu, huheng83@163.com; Rongkang Yang, Yrkaoc@cma.gov.cn 
precipitation prediction is limited. Lidars can observe the vertical water vapor profile; however, their effective range is limited by the presence of clouds. ${ }^{11}$ At the end of the 20th century, ground-based remote sensing instruments, such as those of the Global Navigation Satellite System (GNSS) ${ }^{12,13}$ and ground-based microwave radiometers (MWRs) ${ }^{14,15}$ were used for the continuous monitoring of atmospheric parameters such as the precipitable water vapor (PWV) at a high temporal resolution ranging from seconds to minutes, which is critical to improving the accuracy of the numerical prediction of precipitation. ${ }^{16}$

MWRs use microwave radiation in the 22- to 200-GHz frequency band to measure the water vapor density and temperature profiles from the surface to a height of $10 \mathrm{~km}$. The temperature distribution is obtained by measuring the radiation intensity or brightness temperature of oxygen near $60 \mathrm{GHz}$, whereas the water vapor profile is derived using the intensity and shape of the radiation from vapor in the resonance zone at $22 \mathrm{GHz}$ (for wet air) and $183 \mathrm{GHz}$ (for dry air). ${ }^{17}$ The observation is continuous, with a time step of less than $3 \mathrm{~min}$, which is important for observing rapid changes in temperature and humidity associated with the precipitation process ${ }^{18}$ in microscale and mesoscale weather phenomena. ${ }^{18,19}$

The advantages of the GNSS signal include its high spatial and temporal resolution, allweather monitoring capability, extensive observation area, and low cost. ${ }^{20}$ The GNSS signal is refracted and delayed as it passes through the troposphere, and the PWV can be obtained when the refractivity is calculated from the GNSS signal delay. ${ }^{21}$ Rocken et al. ${ }^{12,22,23}$ reported a root mean square error (RMSE) of 1 to $2 \mathrm{~mm}$ between the GNSS PWV and MWR PWV, demonstrating that the total PWV values obtained by the two instruments are relatively similar. Businger et al. ${ }^{24}$ summarized a method of acquiring the PWV from a GNSS receiver while verifying the accuracy of the GNSS PWV using the MWR PWV and RS PWV.

In this study, we compare the PWV, temperature profile, and water vapor density profile retrieved from a domestically produced MWR during the Ultra-Urban Vertical Integrated Meteorological Observation Technology Research and Experiment project to the RS, GNSS Meteorology (GNSS/MET), and European Centre for Medium-Range Weather Forecasts (ECMWF) reanalysis of the same location. This comparison allows us to quantitatively evaluate the accuracy of the PWV obtained from the domestically produced MWR and propose a correction algorithm for its PWV deviation, which provides a reference for domestic manufacturers to improve the moisture measurement performance of MWRs. It also provides a baseline for the future use of the MWR-derived atmospheric vertical humidity distribution in China.

\section{System Description and Data Processing}

\subsection{System Description}

The MWR used in this project, HTG4, was produced by China Airda Electronic Equipment Co., Ltd. and was installed to observe the vertical and horizontal distributions of meteorological elements in the atmosphere as well as the cloud form, ceiling, and clear air turbulence, ${ }^{25,26}$ as shown in Fig. 1. HTG4 uses the observed brightness temperature data to obtain the vertical profiles of temperature, humidity, water vapor, and liquid water, with a total of 93 layers originally, from the surface to a height of $10 \mathrm{~km}$, by neural network retrieval. In this study, we use 47 layers after quality control.

Although MWRs have good detection capability in clear air, ${ }^{16,27,28}$ temperature profile and humidity profile retrieval under cloudy conditions are limited and sometimes even ineffective. ${ }^{29}$ The primary reason is that the infrared radiometer component of an MWR can obtain only the infrared radiation temperature of the air. Therefore, we combine a domestically manufactured millimeter-wave cloud radar (MWCR) called Xiang Yun ${ }^{30,31}$ with the MWR to reduce the temperature and humidity errors. ${ }^{32}$ The MWCR, as shown in Fig. 1, uses a Cassegrain antenna with a circular parabolic reflector to radiate millimeter-wave signals and then receives the scattered signals from the targets. ${ }^{33}$

The RS used in this study, which was launched at the Southern Suburbs Observatory in Beijing, uses an L-band GTS1 digital sonde, which combines pressure, temperature, and humidity sensors and is tracked by high-altitude radar. The co-located GNSS/MET device is a LEICA 
(a)

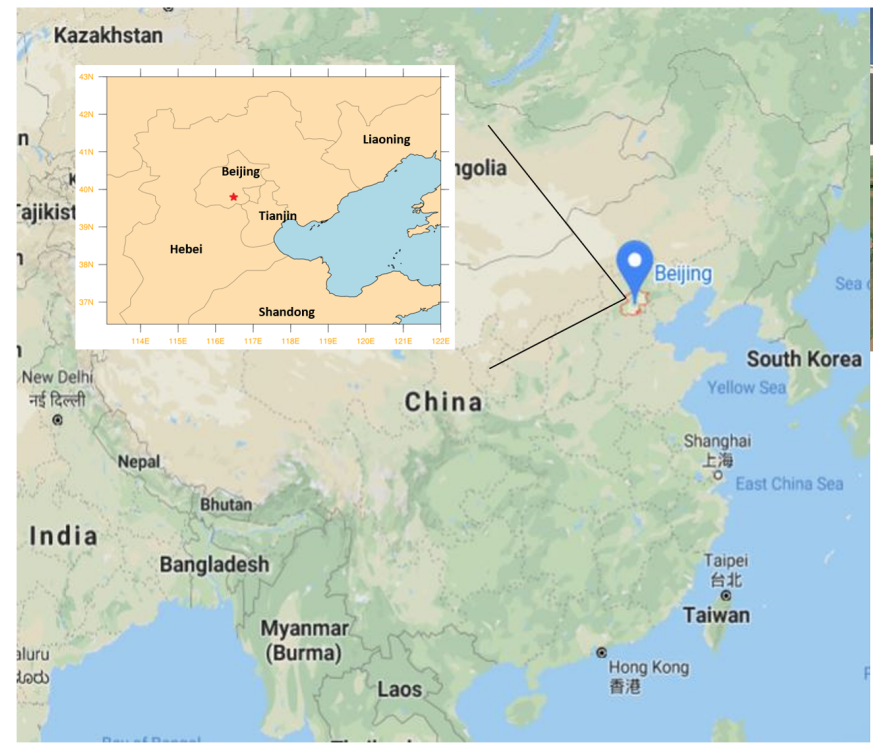

(b)

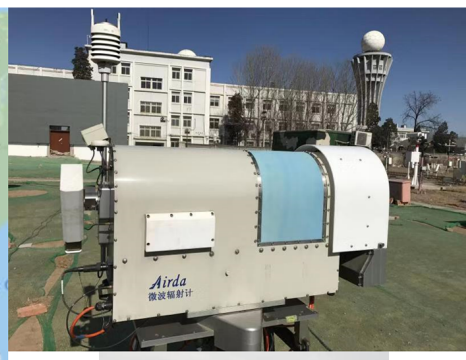

(c)

Fig. 1 (a) Location of the Southern Suburbs Observatory in Beijing (red star). (b) HTG4 MWR. (c) MWCR.

GRX1200+ GNSS receiver manufactured by Leica, Switzerland. The PWV is retrieved using the GAMIT $^{34}$ software developed by the Massachusetts Institute of Technology, and we set a satellite constraint of 0.01 to represent a relative accuracy of $10^{-8}$. The coordinate constraints of the local station are 1,1 , and $2 \mathrm{~m}$, and those of the tracking station are $0.05,0.05$, and $0.1 \mathrm{~m}$, respectively. These values are smaller than those of the target station. ${ }^{35}$ Furthermore, this study uses the total column water vapor with a grid accuracy of $0.125^{\circ} \times 0.125^{\circ}$ from the ERA Interim dataset of the ECMWF reanalysis.

The data used in this study consist of continuous MWR observations from 00:00 on January 1, 2018, to 00:00 on December 24, 2018 (Beijing time, UTC+8). In the same period, a total of 529 RS PWV, 449 GNSS PWV, and 531 EC PWV data were collected. The PWV obtained from the four data sources in different seasons and under different weather conditions are compared and analyzed. We quantitatively analyze the difference between the MWR PWV and the other three observations and propose a correction algorithm. In addition, we use the temperature and water vapor density profiles obtained from the RS and ECMWF in May 2019 to analyze the accuracy of the bright temperature observed by the MWR and then study the source of the differences in the PWV observed by the ground-based MWR.

\subsection{Data Processing}

\subsubsection{PWV retrieval from GNSS/MET}

The GNSS signal is transmitted through the atmosphere along a curve owing to atmospheric refraction, and its speed is lower than that in vacuum. ${ }^{36}$ The total delay distance $\Delta L$ is related to the refractivity as follows: ${ }^{37}$

$$
\Delta L=\int_{s} N \mathrm{~d} s
$$

where $N$ is the atmospheric refractivity and is expressed in terms of the atmospheric properties as follows:

$$
N=\left[-4.03 * 10^{6} \frac{n_{e}}{f}\right]+\left[77.6 \frac{P_{d}}{T}\right]+\left[70.4 \frac{P_{v}}{T}+3.739 \frac{P_{v}}{T^{2}}\right]
$$


where $n_{e}$ is the electron density in the atmosphere, $f$ is the frequency of the electromagnetic wave, $P_{d}$ is the pressure of dry air, $P_{v}$ is the pressure of humid air, and $T$ is the atmospheric temperature. The first two terms can be subtracted from the total delay to obtain the total wet delay $\Delta L_{w}$. The relationship between the zenith wet delay (ZWD) and total wet delay is given by

$$
\mathrm{ZWD}=\Delta L_{w} \cos \theta
$$

where $\theta$ is the zenith angle. The vertical $(z)$ total water vapor in the atmosphere is

$$
\mathrm{PWV}=\int \rho_{v} \mathrm{~d} z
$$

where $\rho_{v}$ is the water vapor density in the air.

Bevis et al. ${ }^{37}$ proved that the ZWD is related to the PWV as follows:

$$
\mathrm{PWV}=\prod * \mathrm{ZWD}
$$

where $\Pi$ is a mapping function that can be calculated as follows:

$$
\prod=\frac{10^{6}}{\rho R_{v}\left[\frac{k_{3}}{T_{m}}+k_{2}-\omega k_{1}\right]},
$$

where $k_{1}, k_{2}, k_{3}$, and $\omega$ are the physical constants, $\rho$ is the water vapor density, $R_{v}$ is an atmospheric constant related to the water vapor, and $T_{m}$ is the average temperature of the atmosphere, which is related to the ground temperature and the vertical structure of the temperature. $T_{m}$ is commonly expressed by Braun's empirical formula: ${ }^{38} T_{m}=70.2+0.72 T_{s}$, where $T_{s}$ is the bright temperature of the cosmic background radiation. However, owing to geographical differences, the Bevis model may produce a systematic deviation between regions. To obtain the most accurate precipitation according to the water vapor, regression analysis can be used to establish parameters that are suitable for different regions.

\subsubsection{PWV retrieval from $R S$}

In this study, the temperature $T$ in the L-band sounding data and the triple-point temperature of water are used to calculate the saturated vapor pressure on the surface $\left(E_{w}\right)$, as shown by the Goff-Gratch formula:

$$
\begin{aligned}
\log E_{w}= & 10.79574\left(1-\frac{T_{0}}{T}\right)-5.028 \log \frac{T}{T_{0}}+1.50475 \times 10^{-4}\left[1-10^{-8.2969\left(\frac{T}{T_{0}}-1\right)}\right] \\
& +0.42873 \times 10^{-3}\left[10^{4.76955\left(1-\frac{T_{0}}{T}\right)}-1\right]+0.78614 .
\end{aligned}
$$

Then we use $E_{w}$ to calculate the actual vapor pressure $e$ :

$$
e=E_{w}\left(\frac{U}{100}\right)
$$

The water vapor density in the atmosphere, $\rho_{v i}$, is calculated as follows: ${ }^{39}$

$$
\rho_{v i}=216.7679 * \frac{e}{T}
$$

Finally, the water vapor density $\rho_{v i}$ is accumulated by height to obtain the PWV. 


\subsubsection{PWV retrieval from MWR}

According to the atmospheric radiation transfer equation, the ground-based MWR uses the brightness temperature obtained from the channel to remotely measure the atmospheric PWV, which can be calculated as follows: ${ }^{40}$

$$
T_{\mathbf{B}}=T_{S} \tau(0, \infty)+\int_{0}^{\infty} T(z)\left[-\frac{d \tau(0, \infty)}{d z}\right] \mathrm{d} z
$$

The above equation can be rewritten as follows:

$$
T_{\mathbf{B}}=T_{S} \tau(0, \infty)+T_{m}[1-\tau(0, \infty)]
$$

where $T(z)$ is the temperature at height $z$, and $\tau(0, \infty)$ is the atmospheric transmittance.

$$
T_{m}=\frac{\int_{\tau(0, \infty)}^{1} T(z) d \tau(0, z)}{1-\tau(0, \infty)}
$$

To remove the effects of precipitation, the atmospheric permeability, which is affected mainly by the PWV and liquid water content, can be expressed as

$$
\tau(0, \infty)=\tau_{\mathrm{V}}(0, \infty) \tau(0, \infty) \approx e^{\frac{V}{V_{0}}} * e^{\frac{L}{L_{0}}} \approx\left(1-\frac{V}{V_{0}}\right)\left(1-\frac{L}{L_{0}}\right),
$$

where $A$ and $B$ are the water vapor transmission rate and liquid water transmission rate, respectively, $V$ is the PWV, and $L$ is the liquid water content. $V_{0}$ and $L_{0}$ are constants and are determined by the frequency of the ground-based MWR. Substituting Eq. (13) into Eq. (11) gives

$$
T_{\mathbf{B}}=T_{S}+\left(T_{m}-T_{S}\right)\left(\frac{V}{V_{0}}+\frac{L}{L_{0}}\right)
$$

The brightness temperature received by the ground-based MWR is linearly related to $V$ in certain frequency bands. Using the observations of the ground-based MWR at more than two frequencies, $V$ can be obtained as

$$
V=A_{0}+A_{1} T_{B 1}+A_{2} T_{B 2}
$$

where $T_{B 1}$ and $T_{B 2}$ are the brightness temperatures received in two channels of the ground-based MWR, and the coefficients $A_{0}, A_{1}$, and $A_{2}$ are calculated by statistical regression using historical RS data.

We obtained the water vapor density profile from the MWR data, which is equivalent to that from the $\mathrm{RS}^{41}$

\section{Results}

\subsection{Analysis of Retrieved PWV}

\subsubsection{Comparison of PWV results}

Figure 2 shows the monthly diagram of PWV retrieval from the MWR, RS, GNSS/MET, and ECMWF reanalysis from 00:00 January 1, 2018, to 00:00 December 24, 2018 (Beijing time). The RS PWV, GNSS PWV, and EC PWV are correlated, whereas the MWR PWV has outliers owing to precipitation, which appear mainly in the summer (April to September). By contrast, the differences in the PWV from January to March and from November to December are smaller, and the correlations among the PWV results from all the sources are better. The precipitation data at 6-h intervals are added and show that the outliers appear during precipitation. A preliminary analysis suggests that precipitation forms a water film on the radome on the MWR, which 
Hu et al.: Multi-sensor study of precipitable water vapor and atmospheric profiling...
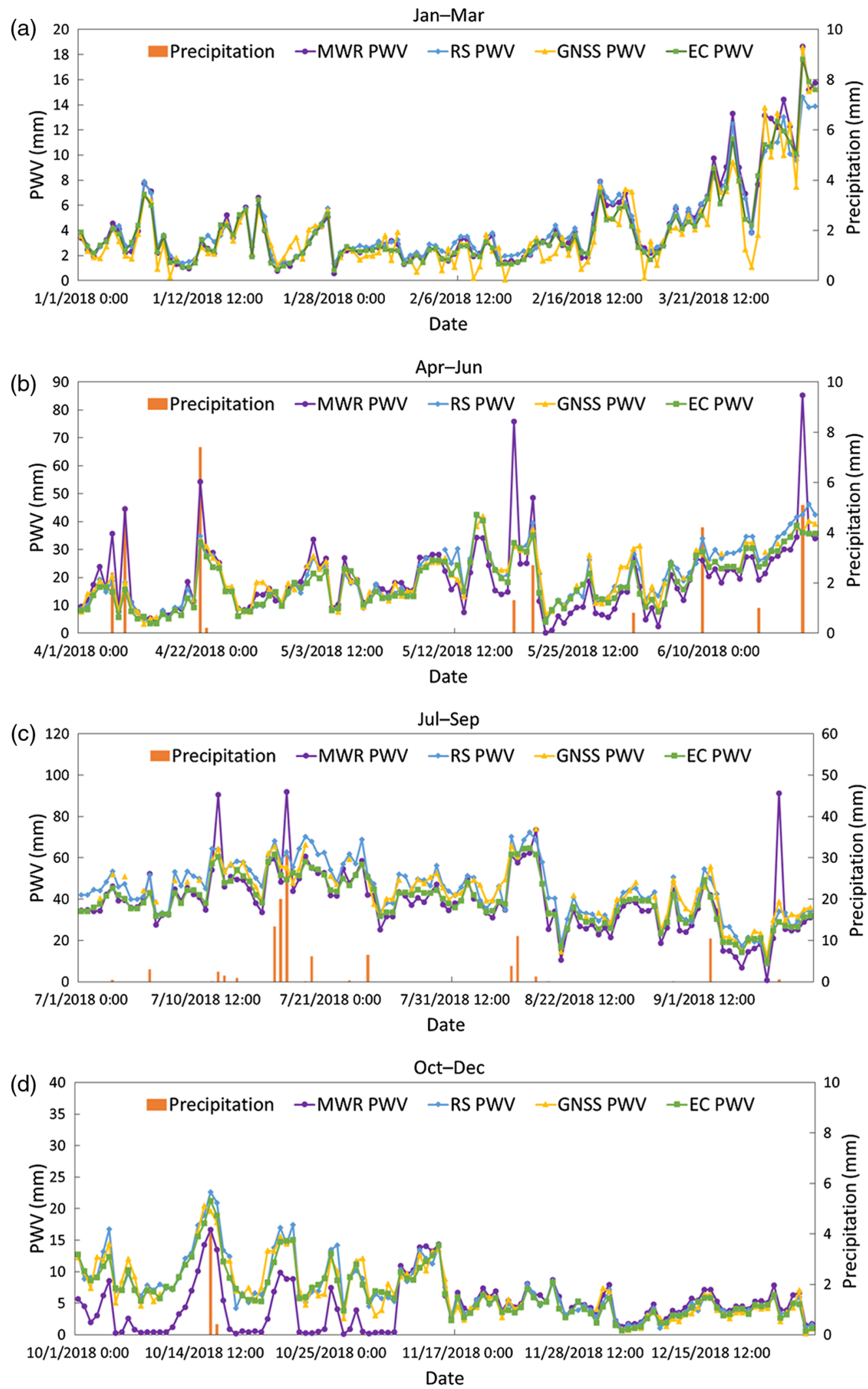

Fig. 2 Comparison of the MWR PWV, GNSS PWV, RS PWV, and EC PWV from January to December 2018. Histograms show the precipitation in (a) January to March, (b) April to June, (c) July to September, and (d) October to December. 
Hu et al.: Multi-sensor study of precipitable water vapor and atmospheric profiling...

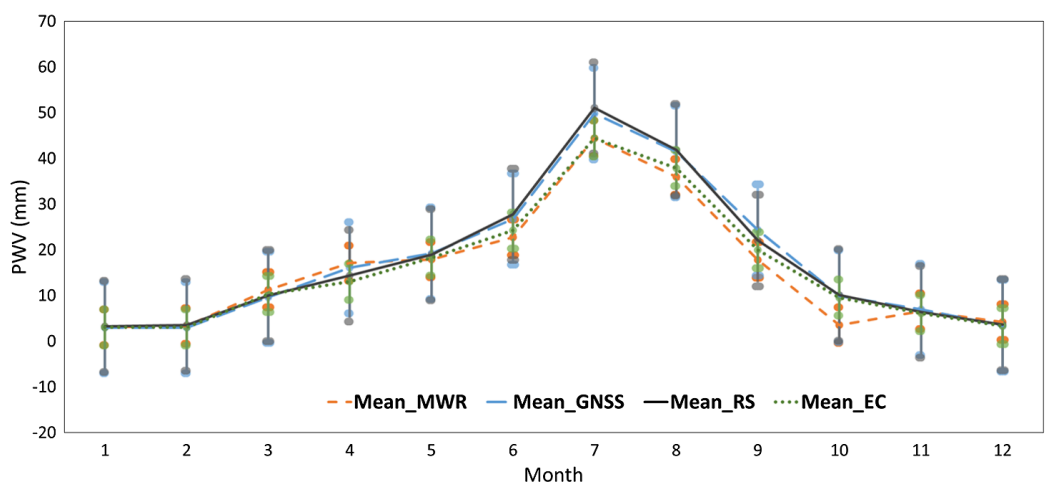

Fig. 3 Monthly average and standard deviation of the MWR PWV (orange short-dashed line), GNSS PWV (blue long-dashed line), RS PWV (black solid line), and EC PWV (green dotted line) from January to December 2018.

contaminates the MVR PWV data; in addition, the retrieval of the MWR data does not take into account the scattering, emission, and absorption effects of the rain. ${ }^{39}$

Figure 3 shows the monthly average and standard deviation of the MWR PWV, GNSS PWV, RS PWV, and EC PWV from January to December 2018. The MWR PWV and EC PWV are lower than those from the RS and GNSS from June to September, whereas the PWV data retrieved from all four instruments are well-correlated in the other months. In addition, the standard deviations of the MWR PWV and EC PWV are smaller than those of the other two datasets, indicating that the MWR PWV and EC PWV are more concentrated.

Figure 4 shows the correlations between each pair of datasets. The GNSS PWV is wellcorrelated with the RS PWV and EC PWV, as the scatter points are evenly distributed on and around the fitting line. The scatter points of the MWR PWV, RS PWV, and EC PWV indicate that

(a)

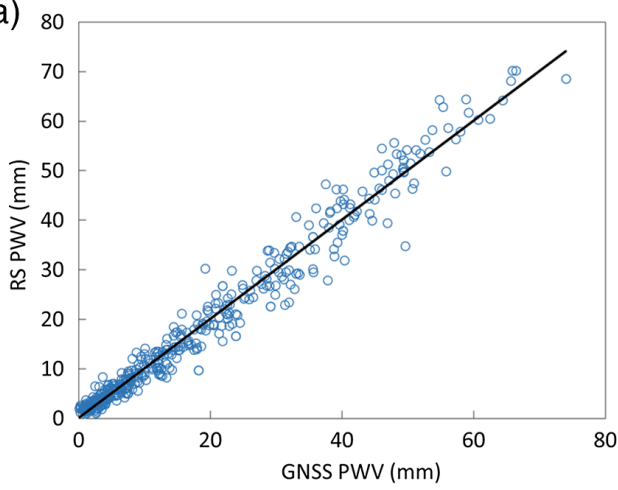

(c) 100

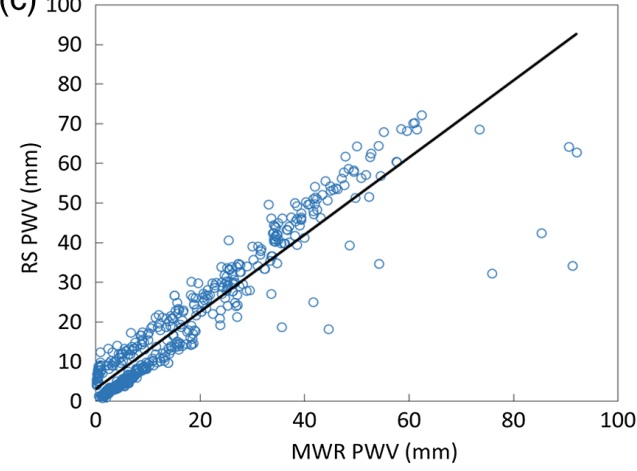

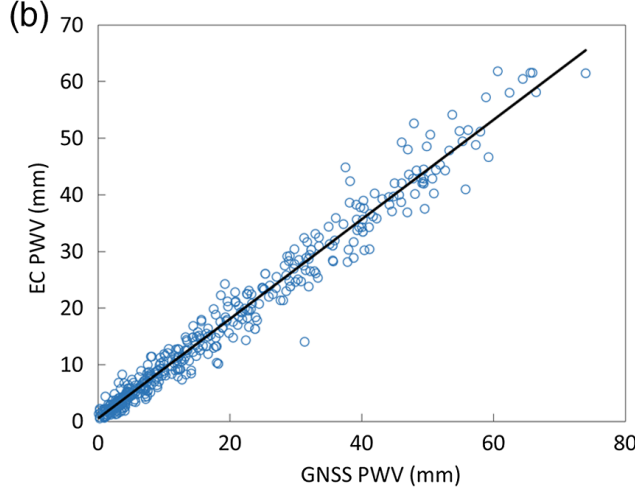

(d)

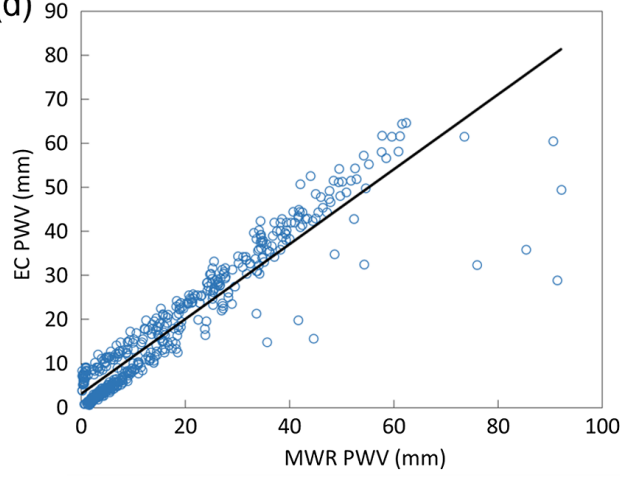

Fig. 4 Scatterplots showing correlations between GNSS PWV and (a) RS PWV and (b) EC PWV. Scatterplots showing correlations between MWV PWV and (c) RS PWV and (d) EC PWV. 
Hu et al.: Multi-sensor study of precipitable water vapor and atmospheric profiling...

Table 1 Comparison of MWR PWV, GNSS/MET PWV, RS PWV, and EC PWV.

\begin{tabular}{lcc}
\hline \hline Comparison & Correlation coefficient & RMSE (mm) \\
\hline MWR PWV versus RS PWV & 0.934 & 17.19 \\
MWR PWV versus EC PWV & 0.933 & 16.05 \\
GNSS PWV versus RS PWV & 0.989 & 17.04 \\
GNSS PWV versus EC PWV & 0.986 & 15.83 \\
\hline \hline
\end{tabular}

there is a bias in the MWR PWV. Table 1 shows that the correlation coefficients between the GNSS PWV and the RS PWV and EC PWV both exceed 0.98, and the correlation coefficients between the MWR PWV and the RS PWV and EC PWV are 0.934 and 0.933, respectively, indicating that the correlation between the MWR PWV and the other three observations is affected by the outliers. The RMSEs between the MWR PWV and the RS PWV and EC PWV are 17.19 and $16.05 \mathrm{~mm}$, respectively, which are larger than those between the GNSS PWV and the RS PWV and EC PWV.

The MWR PWV is less stable than the other three PWVs. There are discrepancies between the PWVs retrieved from the MWR, RS, GNSS/MET, and ECMWF reanalysis, which may be related to the retrieval algorithm. In addition to the effects of precipitation, the reason may be that the MWR uses the observed brightness temperature to obtain information on the atmospheric temperature, water vapor, and humidity using a neural network model that requires many years of ground and RS observation data. The relative humidity data are calculated indirectly from the temperature and water vapor density, which may introduce systematic variation.

The monthly mean differences between the MWR PWV and the RS PWV, GNSS PWV, and EC PWV for all time periods and only for days without precipitation are obtained separately, as shown in Fig. 5. The solid line represents the results for all time periods, and the dotted line represents the results for days without precipitation. Figure 5 shows that the monthly mean differences between the PWV values retrieved from all four datasets are generally greater than zero from January to March and from November to December, whereas the monthly mean differences are less than zero and the absolute values are larger from April to September.

We conclude that the MWR observations are drier than the other observations in summer and wetter in winter. The precipitation data from the station show that the precipitation in the region occurs mainly from April to September 2018. After the PWV data affected by precipitation are removed, the absolute values of the monthly mean differences between the MWR PWV and the other results are larger, because the monthly average of the MWR PWV decreases when the abnormally large values for the days with precipitation are removed. Figure 5 also shows that the monthly mean values of the MWR PWV and EC PWV are relatively similar, and the absolute value of the difference is smaller than the differences between MWR PWV and the RS PWV and GNSS PWV.

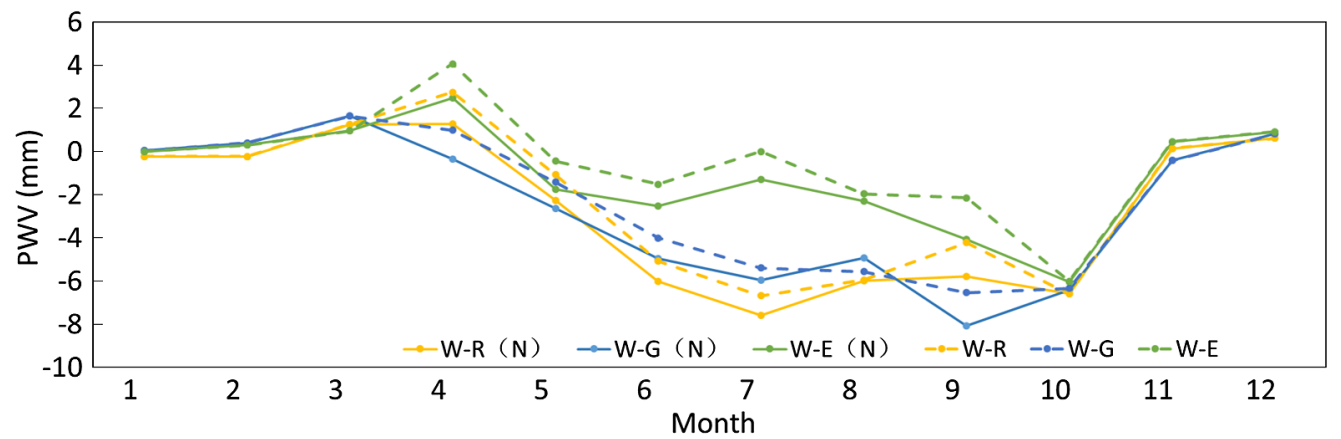

Fig. 5 Monthly mean differences between the MWR PWV and the RS PWV, GNSS PWV, and EC PWV. Solid lines represent the results for all time periods; dashed lines represent the results for only the days without precipitation. 
Hu et al.: Multi-sensor study of precipitable water vapor and atmospheric profiling...

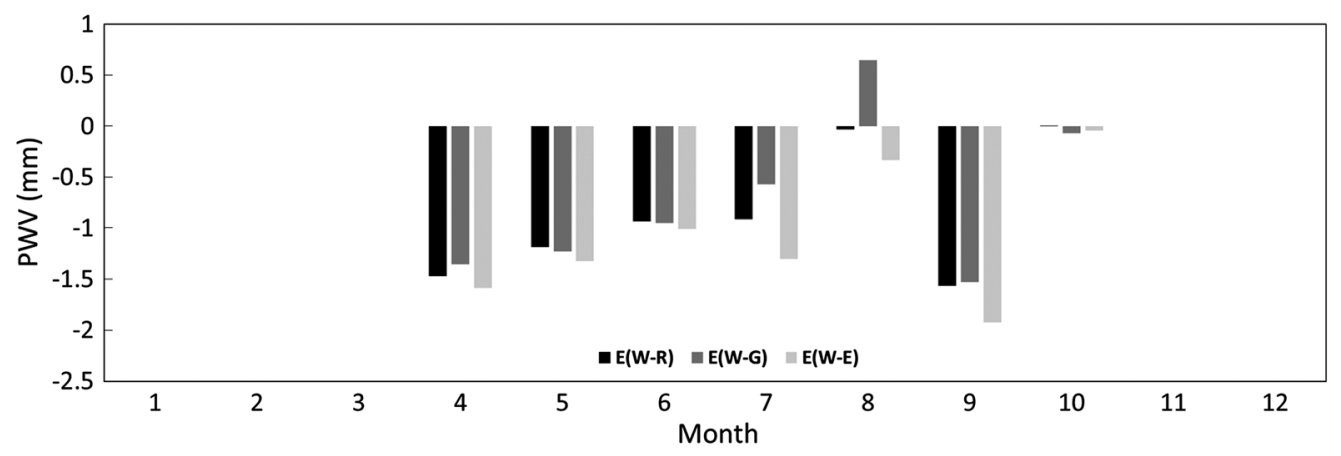

Fig. 6 Comparison of the monthly means for only days without precipitation and for all observation periods. Black: difference between MWR PWV and RS PWV, dark gray: difference between MWR PWV and GNSS PWV, and light gray: difference between MWR PWV and EC PWV.

Figure 6 compares the monthly mean differences between the MWR PWV and the other results for only the days without precipitation and for all time periods. The differences are smallest from April to September, and the absolute values are distributed mainly between 1 and $2 \mathrm{~mm}$. Removing the observations of days with precipitation greatly decreases the difference between the MWR PWV and EC PWV; the maximum difference occurs in September, and the absolute value is $2 \mathrm{~mm}$. The monthly mean difference between the MWR PWV and GNSS PWV in August increases after the precipitation data are removed. This result suggests that the GNSS PWVs for the days with precipitation day were high, and more GNSS/MET observation data were missing in August. The value of the GNSS PWV is unreliable when the solution is recovered from insufficient measurements.

\subsubsection{Correction of MWR PWV data}

First, we obtain the differences between the MWR PWV and the other three datasets after the impact of precipitation is removed. Figure 7 shows that from January to April and in December of 2018, the differences between the datasets, most of which are within $\pm 3 \mathrm{~mm}$, changed slightly. During this period, the surface temperature increased from zero to $\sim 30^{\circ} \mathrm{C}$. The differences between the WMR PWV and the RS PWV and EC PWV are correlated with the surface temperature.

Second, the absolute value of the average differences between the MWR PWV and the RS PWV, EC PWV, and GNSS PWV and the RMSEs are calculated at $2^{\circ} \mathrm{C}$ intervals. Figure 8 shows

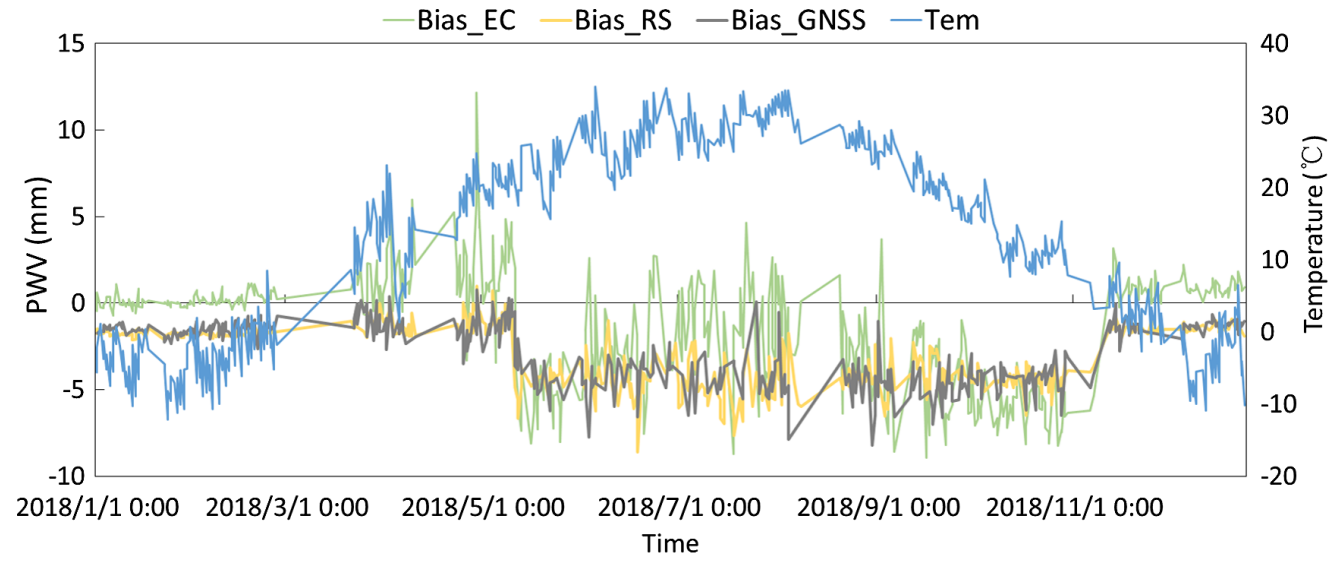

Fig. 7 Timing chart of the differences between MWR PWV and RS PWV, EC PWV, and GNSS PWV and the surface temperature. Green line: difference between MWV PWV and EC PWV, yellow line: difference between MWV PWV and RS PWV, gray line: difference between MWV PWV and GNSS PWV, and blue line: surface temperature. 

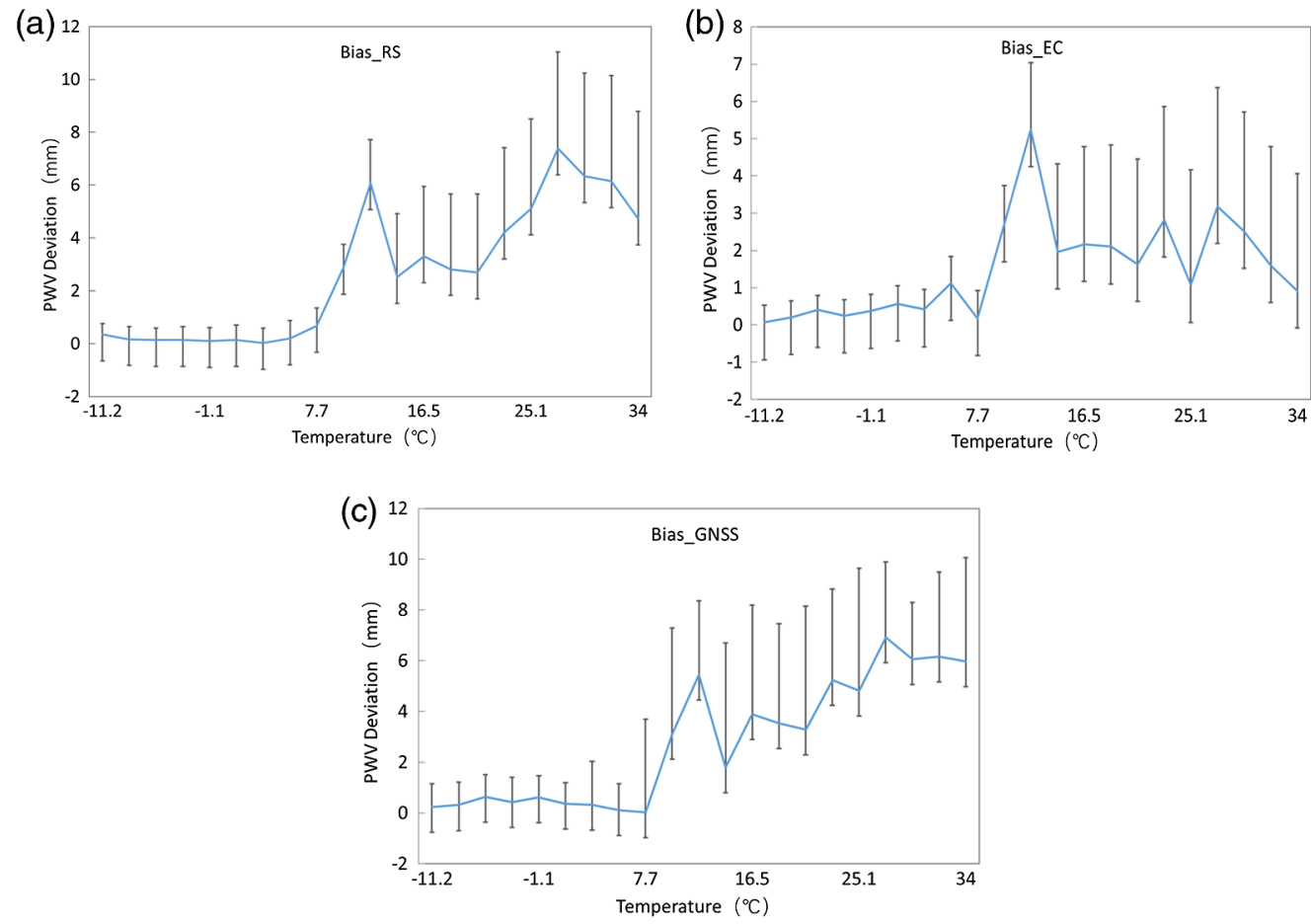

Fig. 8 Absolute values of the average differences between the MWR PWV and (a) RS PWV, (b) EC PWV, and (c) GNSS PWV at $2^{\circ} \mathrm{C}$ intervals. The error bars show the RMSE.

that the absolute values of the differences between the PWV datasets increase with increasing temperature. From $-11.2^{\circ} \mathrm{C}$ to $7.7^{\circ} \mathrm{C}$, the absolute values of the differences are stable and less than $2 \mathrm{~mm}$. When the temperature exceeds $7.7^{\circ} \mathrm{C}$, the absolute value of the PWV difference increases, and the RMSE also increases gradually. The largest difference appears around $12^{\circ} \mathrm{C}$. For the sample observed in this project, the PWV difference becomes more significant with increasing temperature.

Because of insufficient measurements in the GNSS PWV observations, we selected the RS PWV and EC PWV datasets, which have good data continuity and stability, as a reference to analyze the differences in the PWV values retrieved from ground-based MWRs. We analyzed the variation of the differences between the three datasets from May to October 2018 in terms of the surface temperature and performed polynomial fitting to establish an empirical formula for the differences.

$$
B_{R}=0.0069 T^{2}-0.2706 T-4.1739 \quad B_{E}=0.0047 T^{2}+0.0265 T-6.8253,
$$

where $B_{R}$ and $B_{E}$ represent the corrected differences between the MWR PWV and the RS PWV and EC PWV, respectively, and $T$ is the surface temperature (unit: ${ }^{\circ} \mathrm{C}$ ). The fitting results of Eq. (16) were used to correct the MWR PWV. As shown in Fig. 9, the correlation coefficients between the revised WMR PWV and the RS PWV and EC PWV increased to 0.99 and 0.993 , and the RMSEs decreased to 14.13 and $15.86 \mathrm{~mm}$, respectively, indicating that the PWV from the MWR was significantly closer to the RS PWV and EC PWV.

\subsection{Analysis of the Source of Differences in PWV}

Figures 10(a)-10(c) show the temperatures profiles retrieved from the MWR, RS, and ECMWF reanalysis. Although they are well-correlated, differences appear between the profile from the MWR and the other two results, especially below $2000 \mathrm{~m}$. Differences between morning and evening are not clear in the figure when 00 and 12 UTC are calculated separately. Figures 10 (d)-10(f) show the water vapor density profiles retrieved from these three sources. The water vapor density profile of the MWR is also positively correlated with the results of 
Hu et al.: Multi-sensor study of precipitable water vapor and atmospheric profiling...
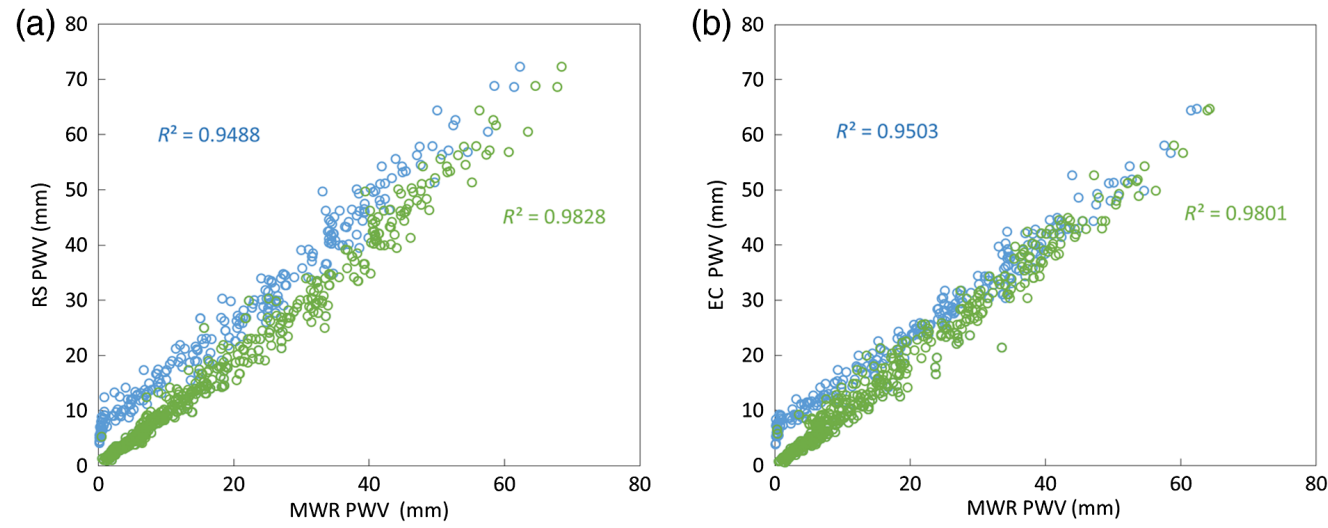

Fig. 9 Scatterplots of (a) RS PWV and (b) EC PWV versus MWR PWV before and after correction for days without precipitation. Blue circles: before correction and green circles: after correction.

(a)

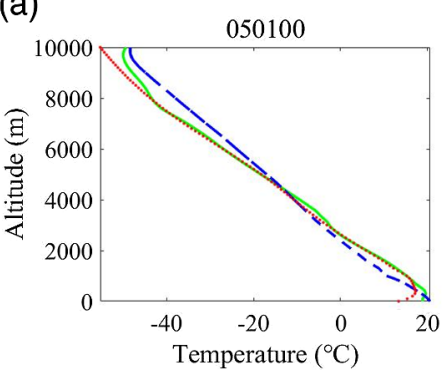

(d)

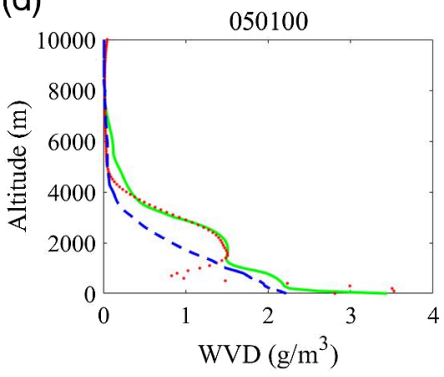

(b)

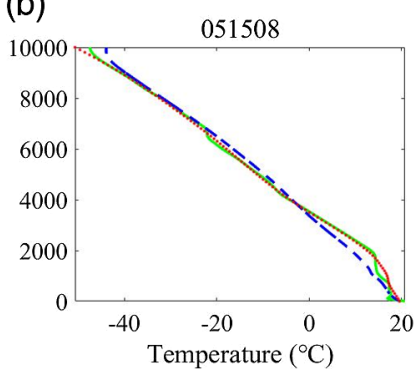

(e)

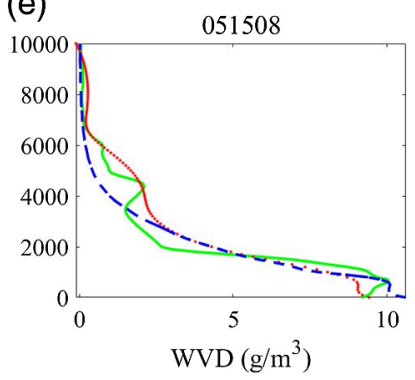

(c)

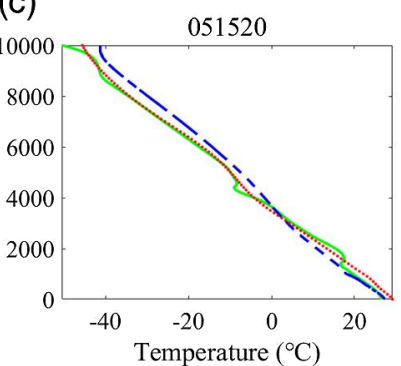

(f)

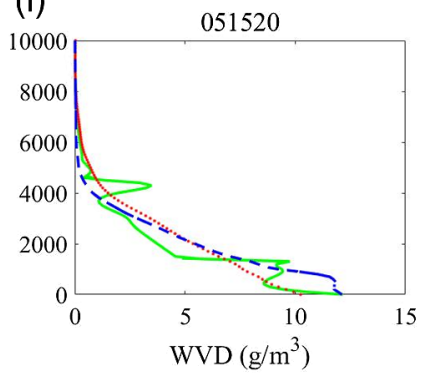

Fig. 10 (a)-(c) Temperature and (d) -(f) water vapor density profiles retrieved from the MWR, RS, and ECMWF reanalysis. Blue long-dotted line: MWV, green line: RS, and red dotted line: ECMWF.

the RS and ECMWF reanalysis. However, the water vapor density profile of the MWR differs significantly from the other two results below $6000 \mathrm{~m}$.

The height resolutions of the profiles retrieved from the MWR, RS, and ECMWF reanalysis are different; therefore, to quantify the differences between the profiles, the heights of the profile results must be interpolated. ${ }^{42}$ The distribution of the atmospheric temperature profiles increased linearly. Figures 11(a) and 11(b) show that the temperature profiles obtained from the ECMWF reanalysis and MWR at 12:00 UTC on May 15 are very similar to the result of linear fitting. The coefficients are all 0.99 , and the RMSEs are $1.05^{\circ} \mathrm{C}$ and $0.93^{\circ} \mathrm{C}$, respectively. In addition, the height separation of the MWR and ECMWF reanalysis is relatively uniform; thus, the temperature profiles from the MWR and ECMWF reanalysis can be linearly interpolated according to the height of each layer of the RS using Eq. (17).

$$
T_{w i}=\left[\left(h_{w i}-h_{r i}\right) /\left(h_{r i+1}-h_{r i}\right)\right] *\left(T_{r i+1}-T_{r i}\right)+T_{r i},
$$

where $h_{r i}$ and $h_{r i+1}$ represent the heights of the upper and lower layers from the MWR, respectively; $T_{r i}$ and $T_{r i+1}$ represent the temperatures corresponding to the heights of the upper and 

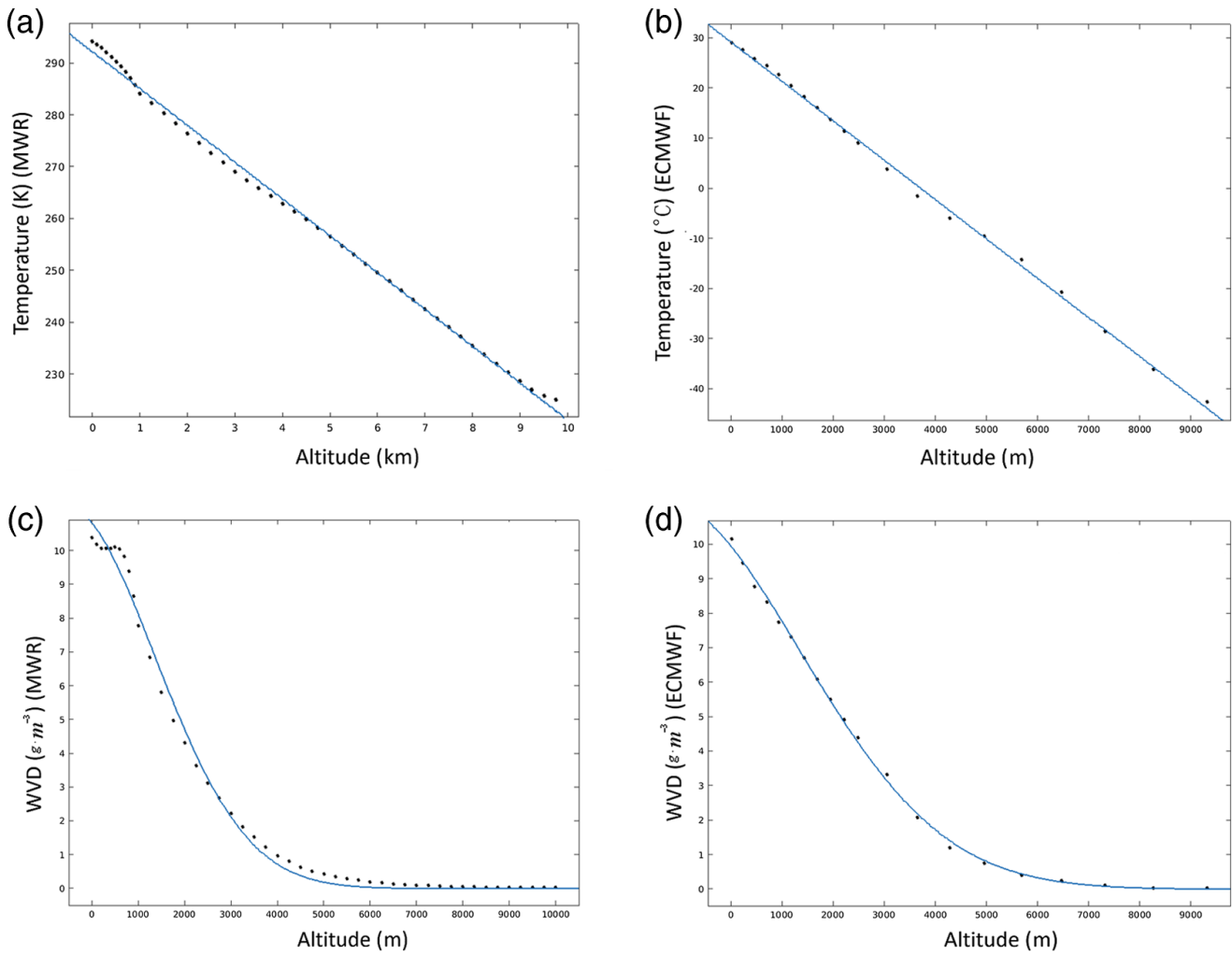

Fig. 11 Linear fitting of the temperature obtained from (a) MWR and (b) ECMWF reanalysis at 12:00 UTC on May 15. Gaussian fitting of the water vapor density retrieved from (c) MWR and (d) ECMWF reanalysis at 12:00 UTC on May 15.

lower layers, respectively; and $h_{w i}$ and $T_{w i}$ represent the height and corresponding temperature to be interpolated, respectively. The same method can be used to obtain the temperature profile from the ECMWF reanalysis.

Figures 11(c) and 11(d) show the water vapor density profiles below $10 \mathrm{~km}$ retrieved from MWR and ECMWF reanalysis at 12:00 UTC on May 15, which are consistent with a Gaussian fitting. The correlation coefficients are both 0.99 , and the RMSEs are 0.29 and $0.13 \mathrm{~g} \cdot \mathrm{m}^{-3}$, respectively. We first use the Gaussian function to fit the water vapor density retrieved from the MWR and then obtain the Gaussian fitting parameters. Finally, we interpolate the height of the RS into the result of the above Gaussian fitting.

$$
W_{r i}=a * \exp \left\{-\left[\left(h_{r i}-b\right) / c\right] \hat{2}\right\}
$$

where $W_{r i}$ represents the water vapor density of each layer, and $a, b$, and $c$ are the Gaussian fitting parameters. We interpolate the height using the following equation: ${ }^{43}$

$$
W_{w i}=W_{r i} * \exp \left[-\frac{\left(h_{r i}-b\right)^{2}-\left(h_{w i}-b\right)^{2}}{c^{2}}\right] .
$$

The correlation coefficients of the temperature profiles between the MWR and the RS and ECMWF reanalysis are both 0.99 , and the RMSEs are $1.58^{\circ} \mathrm{C}$ and $1.26^{\circ} \mathrm{C}$, respectively, after height adjustment. Figure 12 shows the differences between the MWR and the RS and ECMWF reanalysis. The temperatures measured using the three types of data near the surface are similar. However, the difference increases below $2000 \mathrm{~m}$ is generally lower than $0^{\circ} \mathrm{C}$, indicating that the temperature measurement of the MWR is low below $2000 \mathrm{~m}$. The difference decreases with height between 2000 and $6000 \mathrm{~m}$, and reaches $0^{\circ} \mathrm{C}$ at $\sim 4000 \mathrm{~m}$. This is the minimum difference between the temperatures measured by the three types of data. The difference reaches the maximum value, which is between $2^{\circ} \mathrm{C}$ and $6^{\circ} \mathrm{C}$, when the height reaches 6000 to $8000 \mathrm{~m}$, indicating 
Hu et al.: Multi-sensor study of precipitable water vapor and atmospheric profiling...
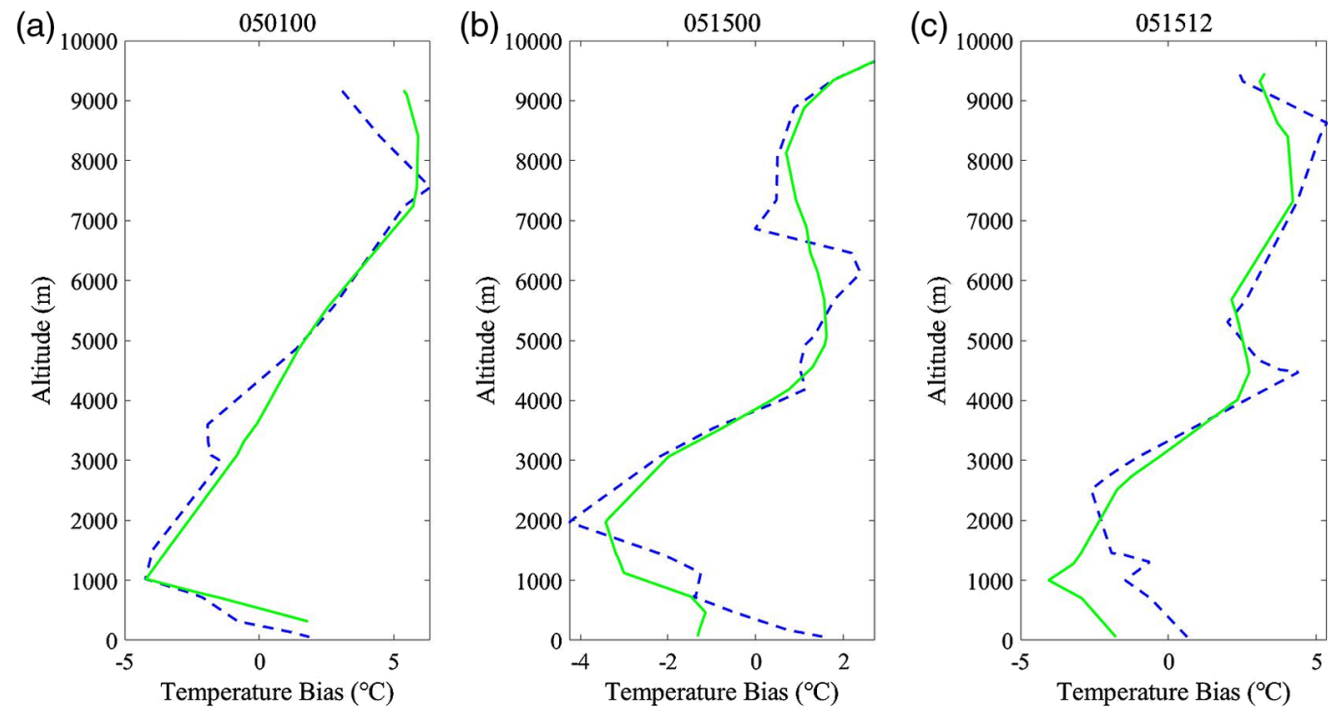

Fig. 12 Temperature differences between the MWR and the RS and ECMWF reanalysis after height unification. Blue dotted line: profile of temperature difference between MWR and RS; green solid line: profile of temperature difference between MWR and ECMWF reanalysis. (a)-(c) Observation times are 00:00 UTC on May 1, 00:00 UTC on May 15, and 12:00 UTC on May 15 , respectively.

that the temperature from the MWR is higher at these heights. The difference in the temperature profile also reflects the difference in the brightness temperature observation by the groundbased MWR. ${ }^{44}$

The correlation coefficients of the water vapor density profile between the MWR and the RS and ECMWF reanalysis are 0.99, and the RMSEs are 0.51 and $0.49 \mathrm{~g} \cdot \mathrm{m}^{-3}$, respectively. The differences in the water vapor density between the three results after height unification are shown in Fig. 13. The water vapor densities of the MWR and ECMWF reanalysis are smaller than that of the RS. However, most of the differences between the MWR and the other results are less than

(a)

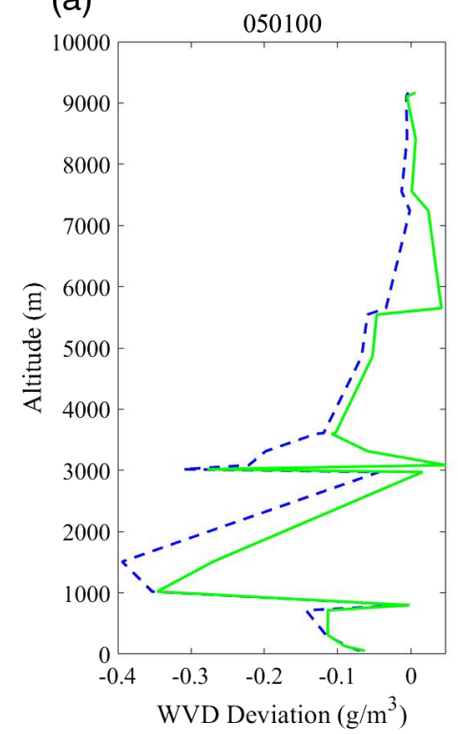

(b)

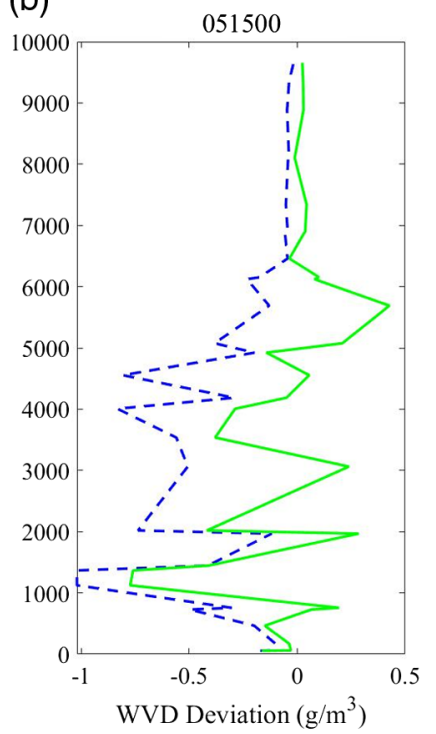

(c)

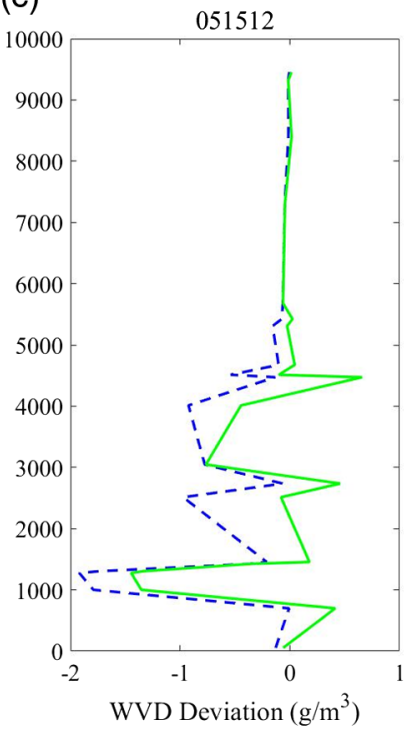

Fig. 13 Water vapor density difference between the MWR and the RS and ECMWF reanalysis after height unification. Blue dashed line: profile of water vapor density difference between MWR and RS; green solid line: profile of water vapor density difference between MWR and ECMWF reanalysis. (a)-(c) Observation times are 00:00 UTC on May 1, 00:00 UTC on May 15, and 12:00 UTC on May 15, respectively. 

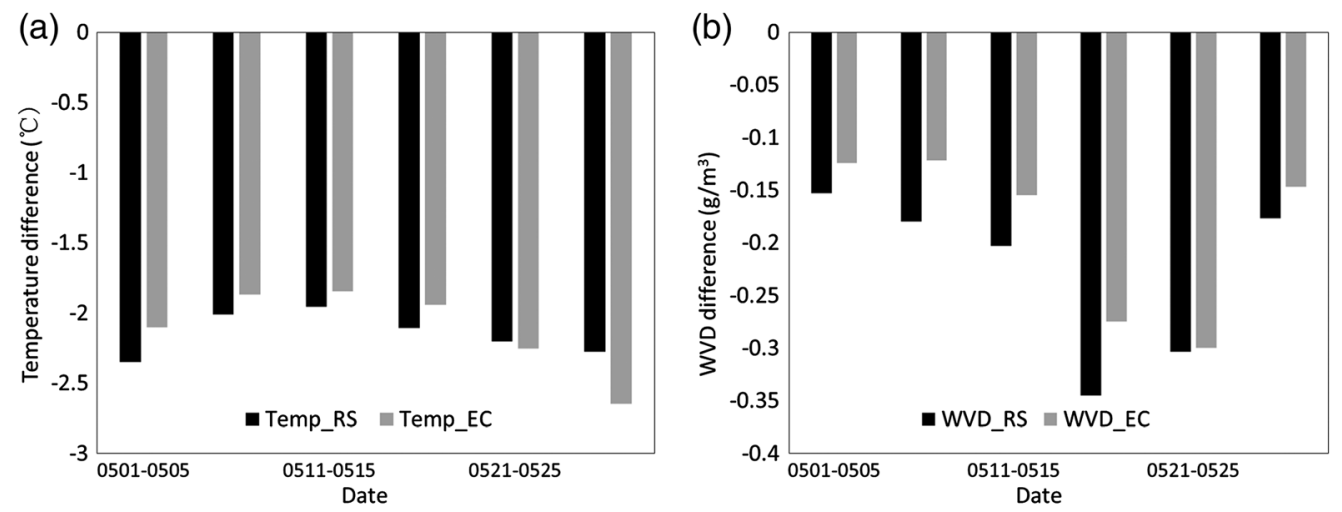

Fig. 14 Average differences between (a) temperature and (b) water vapor density profiles from the MWR, RS, and ECMWF reanalysis from May 1 to 31 at five day intervals. Black: difference between MWR and RS; gray: difference between MWR and ECMWF reanalysis.

$0 \mathrm{~g} \cdot \mathrm{m}^{-3}$ below $6000 \mathrm{~m}$, indicating that the water vapor density observation of the MWR is drier in this height range.

In addition, from the ground to $2000 \mathrm{~m}$, the absolute difference in the water vapor density gradually increases from approximately $0 \mathrm{~g} \cdot \mathrm{m}^{-3}$ to the maximum. Most of the PWV is concentrated below $2000 \mathrm{~m}$, which may explain why the PWV observed by the MWR is drier.

Figure 14(a) shows the average differences between the temperature profiles obtained by the MWR, RS, and ECMWF reanalysis from May 1 to May 31 at five day intervals. The average difference is distributed between $-3^{\circ} \mathrm{C}$ and $-1.5^{\circ} \mathrm{C}$, indicating that the temperature obtained from the MWR is lower. The average absolute differences between the MWR and the RS and ECMWF reanalysis are $2.18^{\circ} \mathrm{C}$ and $2.12^{\circ} \mathrm{C}$, respectively, indicating that the difference between the temperature profiles from the MWR and RS is greater during the observation period. Figure 14(b) shows the average differences between the water vapor density profiles from the RS, ECMWF reanalysis, and MWR in May. The average difference is distributed mainly between -0.35 and $0 \mathrm{~g} \cdot \mathrm{m}^{-3}$, indicating that the water vapor density from the MWR is lower. The average absolute differences are 0.2 and $0.16 \mathrm{~g} \cdot \mathrm{m}^{-3}$, respectively, indicating that the difference between the water vapor density profiles from the MWR and RS is greater during the observation period.

In addition to precipitation, clouds can also affect the brightness temperature observations of ground-based MWRs. ${ }^{45}$ The top panel of Fig. 15 shows the distribution of the humidity obtained

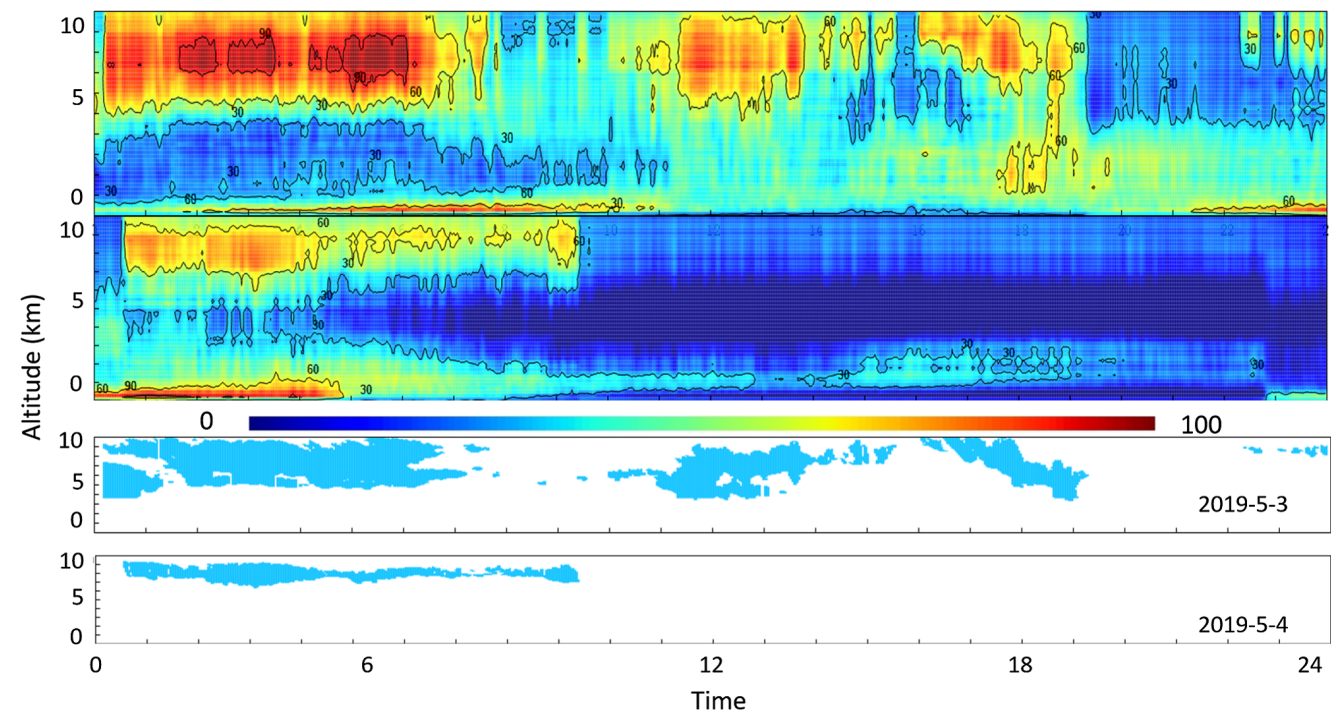

Fig. 15 Humidity distribution from the MWR and cloud distribution observed by MWCR on May 4 and 5 (Beijing time). 
by the MWR for $24 \mathrm{~h}$ from May 4 to 5, Beijing time. The cloud cover detected by the MWCR at the same time is shown at the bottom of Fig. 15. A small amount of cloud cover appears over the station from 00:00 to 01:00 on May 4, and the humidity at heights between 4 and $8 \mathrm{~km}$ is $~ 50 \%$. The absolute differences between the water vapor density profiles retrieved from the MWR and the RS and ECMWF reanalysis are 0.21 and $0.27 \mathrm{~g} \cdot \mathrm{m}^{-3}$, respectively.

Although the humidity from the surface to a height of $5 \mathrm{~km}$ was $\sim 50 \%$ at 20:00 on May 4, there was no cloud cover during this period. The absolute differences between the water vapor density profiles from the MWR and the RS and ECMWF reanalysis were 0.22 and $0.12 \mathrm{~g} \cdot \mathrm{m}^{-3}$, respectively. The absolute differences between the water vapor density profiles measured by the MWR and the RS and ECMWF reanalysis increased to 0.25 and $0.19 \mathrm{~g} \cdot \mathrm{m}^{-3}$, respectively, when the MWCR showed a cloud over the station at 00:00 on May 5. As the cloud dissipated, the absolute differences between the water vapor density profiles dropped to 0.08 and $0.07 \mathrm{~g} \cdot \mathrm{m}^{-3}$, respectively, at 12:00 on May 5. Because the humidity measurement of the RS is unstable when it passes through the cloud, we see only the changes in the absolute difference in the water vapor density profiles measured by the MWR and ECMWF reanalysis. The introduction of MWCR data did not completely remove the effect of clouds on the MWR observations.

\section{Conclusions}

The characteristics of a domestically produced MWR (HTG4) were examined by comparing the PWV and atmospheric profiles retrieved from GNSS/MET, RS, and ECMWF reanalysis. The PWV values retrieved from the MWR were positively correlated with those from GNSS/MET, RS, and ECMWF reanalysis. The MWR PWV is clearly too large when there is precipitation, in agreement with previous studies. ${ }^{29,46}$ The monthly mean differences between the PWV values obtained from the four datasets show that the MWR PWV was smaller in summer and larger in winter. In addition, the differences between the MWR PWV and the RS and GNSS/MET data were larger, whereas that between the MWR PWV and ECMWF reanalysis were smaller. Furthermore, the difference between the MWR PWV and EC PWV was decreased effectively by removing the effects of precipitation. We also found that the difference between the WMR PWV and the RS PWV and EC PWV was correlated with surface temperature. The results were significantly improved using polynomial fitting formulas to correct the differences between them.

The PWV retrieved by the ground-based MWR has a linear relationship with the observed brightness temperature; however, the MWR uses the observed brightness temperature to retrieve information such as atmospheric temperature, water vapor content, and humidity using a neural network model. Further analysis of the temperature and water vapor density profiles retrieved by the MWR revealed that the differences in the temperature profiles below $2000 \mathrm{~m}$ was smaller, whereas the water vapor density profiles below $2000 \mathrm{~m}$ differed the most from those obtained from the other datasets. This result indicates that the accuracy of the brightness temperature observation in this project varies, and this variation is the source of the inaccuracy of the MWR PWV.

In addition to precipitation, clouds also reduce the accuracy of the brightness temperature observed by the MWR. The temperature and humidity profiles obtained by the MWR under cloudy conditions show large errors or could not be obtained. ${ }^{45}$ In this experiment, cloud information from an MWCR was introduced into the model of the MWR to obtain its absorption coefficient and reduce the effects of clouds on observations at high temperature and humidity. However, analysis of the results shows that the effects of clouds and precipitation on the MWR measurements were not completely eliminated. This finding may also explain the relatively low accuracy of ground-based MWR PWV observations. More observations are needed to confirm this conclusion.

\section{Acknowledgments}

We acknowledge grants from the National Key Research and Development Project of China (Grant No. 2017YFC1501700) and the National Natural Science Foundation of China (Grant No. 41705133). 


\section{References}

1. S. Solomon et al., "Contributions of stratospheric water vapor to decadal changes in the rate of global warming," Science 327, 1219-1223 (2010).

2. P. J. Kushner, I. M. Held, and T. L. Delworth, "Southern Hemisphere atmospheric circulation response to global warming," J. Clim. 14, 2238-2249 (2001).

3. J. Lu, G. A. Vecchi, and T. Reichler, "Expansion of the Hadley cell under global warming," Geophys. Res. Lett. 34, L06805 (2007).

4. K. Gui et al., "Evaluation of radiosonde, MODIS-NIR-clear, and AERONET precipitable water vapor using IGS ground-based GPS measurements over China," Atmos. Res. 197, 461-473 (2017).

5. E. Trenberth, J. Fasullo, and L. Smith, "Trends and variability in column-integrated atmospheric water vapor," Clim. Dyn. 24, 741-758 (2005).

6. P. S. Eagleson, "The role of water in climate," Am. Philos. Soc. 144, 33-38 (2000).

7. S. C. Sherwood et al., "Tropospheric water vapor, convection, and climate," Rev. Geophys. Am. Geophys. Union 48(2), RG2001 (2010).

8. T. Wagner et al., "Global trends (1996-2003) of total column precipitable water observed by global ozone monitoring experiment (GOME) on ERS-2 and their relation to near-surface temperature," J. Geophys. Res. Atmos. 111, 2193-2214 (2006).

9. I. M. Held and B. J. Soden, "Water vapor feedback and global warming," Annu. Rev. Energy Environ. 25, 441-475 (2000).

10. A. P. Ferreira, R. Nieto, and L. Gimeno, "Completeness of radiosonde humidity observations based on the Integrated Global Radiosonde Archive," Earth Syst. Sci. Data 11, 603-627 (2019).

11. F. Solheim and J. R. Godwin, "Radiometric profiling of temperature, water vapor and cloud liquid water using various inversion methods," Radio Sci. 33, 393-404 (1998).

12. C. Rocken et al., "Sensing atmospheric water vapor with the Global Positioning System," Geophys. Res. Lett. 20, 2631-2634 (1993).

13. W. L. Smith, "Atmospheric soundings from satellites-false expectation or the key to improved weather prediction," Q. J. R. Meteorol. Soc. 117, 267-297 (1991).

14. F. O. Guiraud, J. Howard, and D. C. Hogg, "A dual-channel microwave radiometer designed for measurements of precipitable water vapor and liquid water," IEEE Trans. Geosci. Electron. 17, 129-136 (1979).

15. H. G. Pascalar, "A survey of multispectral remote sensing techniques for Earth resources applications," Proc. SPIE 0022, 47-64 (1970).

16. J. Gueldner and D. Spankuch, "Remote sensing of the thermodynamic state of the atmospheric boundary layer by microwave radiometry," J. Atmos. Oceanic Technol. 18, 925-933 (2001).

17. C. S. Raju et al., "Microwave radiometric observation of a waterspout over coastal Arabian sea," IEEE Geosci. Remote Sens. Lett. 10(5), 1075-1079 (2013).

18. Radiometrics, Profiler Operator's Manual, Radiometrics Corporation, Boulder Colorado (2007).

19. P. W. Chan, "Performance and application of a multi -wavelength, ground-based microwave radiometer in intense convective weather," Meteorol. Zeits. 18(3), 253-265 (2009).

20. J. Wang and L. Zhang, "Systematic errors in global radiosonde precipitable water data from comparisons with ground-based GPS measurements," J. Clim. 21, 2218-2238 (2007).

21. J. Saastamoinen, "Contributions to the theory of atmospheric refraction," Bull. Geodesique 105, 279 (1972)

22. C. Rocken et al., "GPS sensing of atmospheric water vapor for meteorology," J. Atmos. Oceanic Technol. 12, 468-478 (1995).

23. C. Rocken, T. Van Hove, and R. Ware, "Near real-time sensing of atmospheric water vapor," Geophys. Res. Lett. 24, 3221-3224 (1997).

24. S. Businger et al., "The promise of GPS in atmospheric monitoring," Bull. Am. Meteorol. Soc. 77, 5-18 (1996).

25. E. R. Westwater and M. T. Decker, "Application of statistical inversion to ground-based microwave remote sensing of temperature and water vapor profile," in Inversion Methods 
Hu et al.: Multi-sensor study of precipitable water vapor and atmospheric profiling...

in Atmospheric Remote Sounding, A. Deepak, Ed., pp. 395-428, Academic Press, New York (1997).

26. E. R. Westwater, S. Crewell, and C. Mätzler, "Frontiers in surface-based microwave and millimeter wavelength radiometry," IEEE Geosci. Remote Sens. Symp. IGARSS'04 Proc. Vol. 2, pp. 1268-1272 (2004).

27. D. Cimini et al., "Thermodynamic atmospheric profiling during the 2010 Winter Olympics using ground-based microwave radiometry," IEEE Trans. Geosci. Remote Sens. 49(12), 4959-4969 (2011).

28. K. Knupp et al., "Ground-based passive microwave profiling during dynamic weather conditions," J. Atmos. Oceanic Technol. 26, 1057-1073 (2009).

29. G. Xu et al., "Observational comparison among microwave water radiometer, GPS Radiosonde and GPS/MET," Torrential Rain Disasters 29(4), 315-321 (2010).

30. R. A. Krofli and R. D. Kelly, "Meteorological research applications of MM-wave radar," Meteorol. Atmos. Phys. 59(1-2), 105-121 (1996).

31. L. Zhong, L. Liu, and R. Ge, "Characteristics about the millimeter-wavelength radar and its status and prospect in and abroad," Adv. Earth Sci. 24(4), 383-391 (2009).

32. J. C. Liljegren, "A laboratory combining microwave radiometer and millieter cloud radar to improve integrated liquid water retrievals," in Ninth ARM Sci. Team Meeting Proc., San Antonio, Texas, pp. 636-643 (1999).

33. S. Li et al., "Analysis of cloud base heights observed by cloud radar and ceilometer," Meteorol. Mon. 41(2), 212-218 (2015).

34. T. A. Herring et al., "Gamit reference manual," Release 10.7. 2018 (2018).

35. T. A. Herring et al., GAMIT Reference Manual GPS Analysis at MIT Release 10. 6., Massachusetts Institute of Technology, Boston, Cambridge (2015).

36. A. E. Niell, "Global mapping functions for the atmosphere delay at radio wavelength," J. Geophys. Res. 101, 3227-3246 (1996).

37. M. Bevis et al., "GPS meteorology: remote sensing of atmospheric water vapor using the global positioning system," J. Geophys. Res.: Atmos. 97, 15787-15801 (1992).

38. J. Braun, C. Rocken, and R. Ware, "Validation of line-of-sight water vapor measurements with GPS," Radio Sci. 36, 459-472 (2001).

39. G. Xu et al., "Effect of off-zenith observation on reducing the impact of precipitation on ground-based microwave radiometer measurement accuracy in Wuhan," Atmos. Res. 140-141, 85-94 (2014).

40. H. Niu, Research on Inversion Method of Air Water Vapor Content Based on Microwave Radiometer, pp. 1-66, Henan Normal University (2016).

41. J. Liu, H. Guo, and Y. Li, Calculation Basis of Physical Quantities for Weather Analysis and Forecast, Meteorological Press (2005).

42. Y. Yao and Y. F. Hu, "An empirical zenith wet delay correction model using piecewise height functions," Ann. Geophys. 36, 1507-1519 (2018).

43. Y. Hu and Y. Yao, "An accurate height reduction model for zenith tropospheric delay correction using ECMWF data," in China Satellite Navigation Conf. 2017 Proc., Vol. III, pp. 337-348 (2017).

44. Y.-Y. Liu et al., "Research of BP neural network for microwave radiometer remote sensing retrieval of temperature, relative humidity, cloud liquid water profile," Plateau Meteorol. 29(6), 1514-1523 (2010).

45. C. Gu et al., "Effects of cloud parameter on brightness temperature computation in microwave band," J. Appl. Meteorol. Sci. 27(3), 380-384 (2016).

46. R. Renju et al., "Microwave radiometer observations of interannual water vapor variability and vertical structure over a tropical station," J. Geophys. Res. Atmos. 120, 4585-4599 (2015).

Heng $\mathbf{H u}$ is a senior engineer of the China Meteorological Administration. She graduated with a master's degree in signal and information processing from Nanjing University of Information Technology, China. Her main research areas are retrieving precipitable water vapor from the GPS and Beidou navigation satellite systems, building three-dimensional water vapor tomography models and using the ground-based satellite remote sensing data to verify and analyze the water vapor observation accuracy of Fengyun series satellite and microwave radiometers. 
Hu et al.: Multi-sensor study of precipitable water vapor and atmospheric profiling...

Rongkang Yang is a senior engineer at the China Meteorological Administration. His main research area is vertical observation, especially in the research of sounding and microwave radiometer observation technology.

Wen-Chau Lee is a senior scientist at the NCAR Earth Observing Laboratory in the U.S. His main research areas are radar meteorology and remote sensing observation.

Yunchang Cao is a senior scientist at the China Meteorological Administration. As the founder of GNSS/MET, he currently leads the work of the satellite navigation meteorological application team.

Jiajia Mao is a senior engineer at China Meteorological Administration, mainly engaging in the research and development of new meteorological observation instruments, collecting and publishing data sets of observation experiments.

Lina Gao is a senior engineer at China Meteorological Administration. She is mainly engaged in the research of atmospheric chemistry and the application of lidar numerical models. 